\title{
Vulnerability of patients with chronic obstructive pulmonary disease according to gender in China
}

This article was published in the following Dove Press journal:

International Journal of COPD

19 December 2012

Number of times this article has been viewed

\author{
Peian Lou' \\ Yanan Zhu ${ }^{2}$ \\ Peipei Chen' \\ Pan Zhang' \\ Jiaxi Yu' \\ Ning Zhang' \\ Lei Zhang' \\ Hongmin $\mathrm{Wu}^{2}$ \\ Jing Zhao ${ }^{2}$ \\ $\mathrm{Na}$ Chen' \\ 'Xuzhou Center for Disease Contro \\ and Prevention, ${ }^{2}$ Department of \\ Respiratory Medicine, Affiliated \\ Hospital of Xuzhou Medical College, \\ Xuzhou City, Jiangsu Province, \\ Xuzhou, China
}

Correspondence: Peian Lou Xuzhou Center for Disease Control and Prevention, 142 West Erhuan Road, Xuzhou City, Jiangsu Province,

Xuzhou 221006, China

Tel +865168595 6785

Fax +865I68595 6785

Email loupeian2004@yahoo.com.cn
Background: Little information is available regarding the vulnerability of patients with chronic obstructive pulmonary disease (COPD) in China. We aimed to assess this according to patient gender.

Methods: A cross-sectional study was conducted in the rural area of Xuzhou in China. We interviewed and administered questionnaires to 2825 male and 2825 female patients with COPD and subjected the data generated to statistical analysis. We compared differences between proportions of male and female patients using the $\chi^{2}$ test.

Results: The rate of current smoking in men was $30.1 \%$, whereas that in women was $10.9 \%$, and $31.5 \%$ of men had a history of using biomass fuel compared with $75.3 \%$ of women. Further, $26.0 \%$ of the male patients and $16.4 \%$ of the female patients did not take theophylline regularly when their disease was stable. During acute exacerbations, $65.8 \%$ of the male patients and $39.7 \%$ of the female patients took theophylline or similar drugs. The average potential shortening of life expectancy was 1.76 years for men and 1.18 years for women. The average indirect economic burden was 11158.4 yuan for men and 7481.2 yuan for women. The quality of life was worse in female patients than in male patients.

Conclusion: We found that patients with COPD were vulnerable and that factors determining vulnerability were different for men than for women. Therefore, we recommend adopting different measures for men and women when attempting to prevent, control, and treat COPD, rehabilitate these patients, and improve their quality of life.

Keywords: chronic obstructive pulmonary disease, gender, vulnerability

\section{Introduction}

Chronic obstructive pulmonary disease (COPD) is a progressive disease defined by a limitation of airflow that is at least partially irreversible. ${ }^{1}$ It is a 1eading cause of increased morbidity and mortality, being estimated to rank seventh worldwide as a disease burden and third as a cause of death. ${ }^{2-4}$ In China, COPD affects $8 \%$ of people aged 40 years or older. ${ }^{5}$ Every year, there are over 40 million patients with COPD in China and its annual death toll is over 1.28 million. COPD disables about 5-10 million of these people, preventing them from working and earning a living. ${ }^{6}$ In addition to seriously impacting ability to work and quality of life, patients with COPD use a lot of medical resources and impose a heavy economic burden on society. In China, the annual direct medical costs per capita for patients with COPD are as high as 11,744 yuan, and indirect medical expenses (including transportation, buying health care products, nursing costs) cost about 1570 yuan. ${ }^{7}$ However, so far, the Chinese government has no countrywide program for preventing COPD and treating patients with the disease. 
Prevention and treatment of patients with COPD depends on the ability of patients to recognize the condition. The vulnerability of a population is reflected by the possibility and extent of population health losses caused by various factors or changes in the health system. The vulnerability of a population also reflects its sensitivity to risks, ${ }^{8}$ and is mainly determined by people's resistance or susceptibility to disease, and high vulnerability is associated with prolonged recovery. ${ }^{9}$ The vulnerability of COPD patients is determined by their knowledge about COPD, high-risk behavior, management of their COPD, burden of disease, and many other factors that are influenced by the patient's behavior, social environment, and medical history.

To evaluate the vulnerability of people, things, or events, we must first identify the factors that lead to vulnerability. Once these have been identified, we can make interventions aimed at reducing susceptibility and increasing resilience. Therefore, study of the degree of vulnerability of patients with COPD can provide a scientific basis for developing targeted control measures. In China, factors causing COPD in men and women are significantly different. ${ }^{10}$ Vulnerability may also differ between male and female patients, and there is still a lack of research in this area in China. In the present study, we investigated the vulnerability of male and female patients to COPD, with the aim of providing a scientific basis for interventions to prevent and treat COPD in large community-based settings in China and other countries.

\section{Materials and methods}

\section{Study population}

We selected 8217 patients with COPD randomly from 14 towns in the Xuzhou area. COPD was diagnosed by the standards outlined in the Global Initiative for Chronic Obstructive Lung Disease (GOLD). ${ }^{1}$ How we selected the patients for this research has been described elsewhere. ${ }^{11}$ In the present study, we matched patients enrolled with COPD by age ( \pm one year), number of family members ( \pm one member), education level, stage according to GOLD criteria, and duration of disease. To eliminate factors that would seriously affect COPD-related data, we excluded patients with severe heart, liver, kidney, and lung diseases and those with nervous or mental disorders. We also excluded patients with insufficient data available. Finally, we included 5900 cases in the study (Figure 1).

\section{Questionnaire design}

In preparation for designing the vulnerability questionnaire, we consulted with COPD experts concerning epidemiology, prevention, treatment, and rehabilitation, and reviewed some relevant domestic and foreign published papers. ${ }^{12-14} \mathrm{We}$ then designed the questionnaire and determined that it had high reliability (0.88) and validity (0.86). It consists of 100 items and has five subscales: namely, demographic data (10 items), patient knowledge about COPD (15 items), behaviors (five items), disease management (10 items), quality of life assessment using the Saint George's Respiratory Questionnaire (SGRQ), ${ }^{12}$ and economic burden (10 items). The SGRQ is a standardized, self-administered, pulmonary-specific health status questionnaire containing 50 items and 76 weighted responses with three subscales, namely symptoms (eight items), activity (16 items), and impacts (26 items). The total score varies from 0 to 100 , with higher scores indicating worse health status.

\section{Measurement of exposure to relevant factors and confounders}

We interviewed the 5900 patients with COPD face to face in their homes. We recorded responses to the items about age, gender, current employment status, level of education, cigarette smoking status, marital status, physical activity, family history of COPD, and other factors using the questionnaire we had designed. We ascertained and recorded inpatient costs (including the cost of patient transportation and meals, costs incurred by their escorts, and wages paid to caregivers), outpatient costs (including those for outpatient accommodation), in-home treatment costs, costs of long-term medication regimens (including prescribed drugs purchased at the patient's own expense and self-medication drugs), and costs related to lost productivity and lost employment during the previous year by examining patients' hospital records and their logs in township and village clinics. We ascertained the patients' per capita incomes and life expectancies from data in the Xuzhou Statistical Yearbook and Resident Annual Deaths Report of 2008.

We calculated direct economic burdens based on data from our questionnaire. We estimated indirect economic burdens using data about local per capita income and life expectancy from 2008. To estimate the risk of premature death, we assessed the years of potential life lost (YPLL) as a result of COPD per 100,000 people. According to local life expectancy statistics, the average age at death is 70 years. Therefore, the YPLL is the difference between 70 years and the patient's age at time of death. Using the 2000 census report, we ascertained the age composition of China's population and used this to adjust the composition of the population of Xuzhou city in 2008. We calculated the YPLL according 


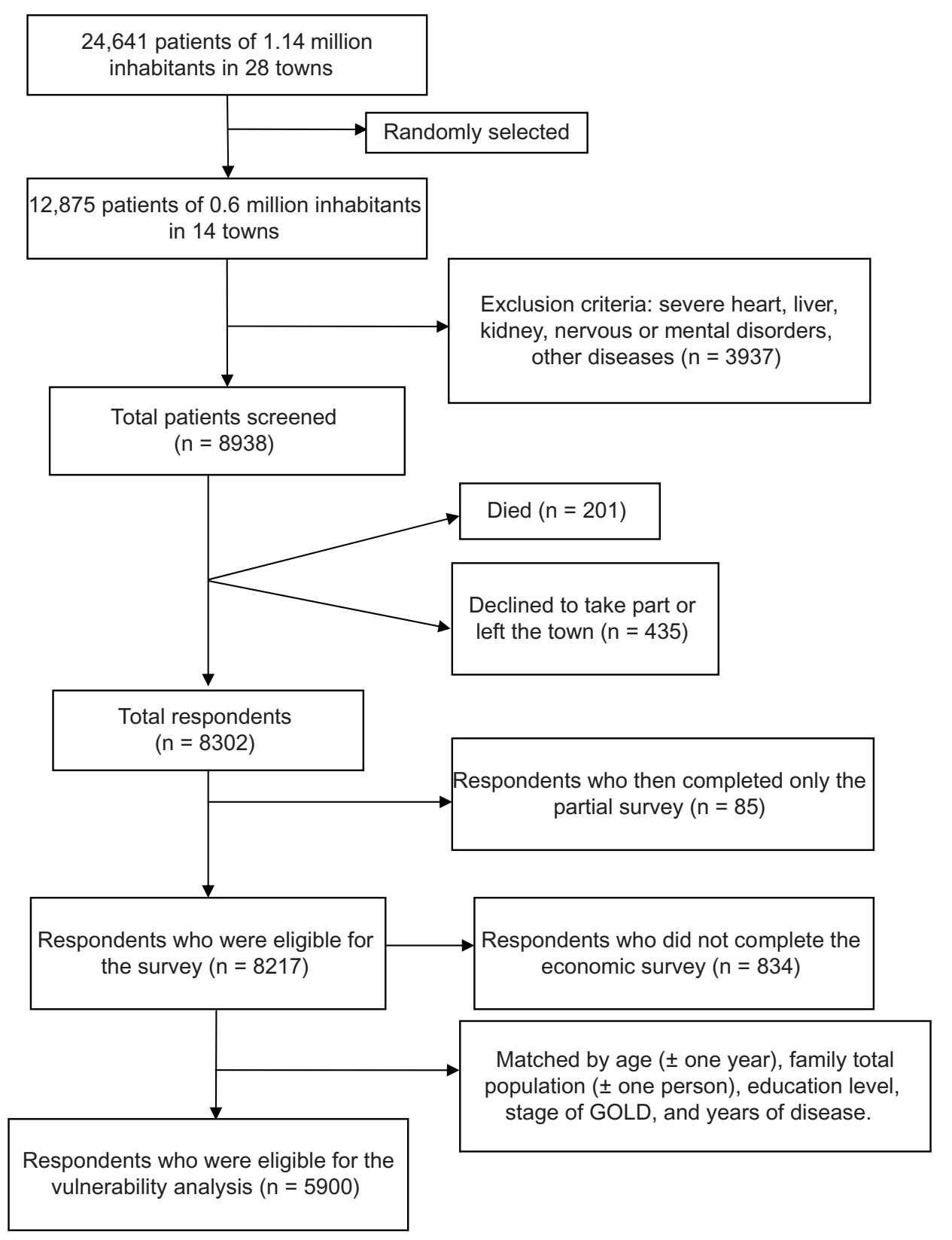

Figure I Study structure: sample selection.

Abbreviation: GOLD, Global Initiative for Chronic Obstructive Lung Disease.

to the following equation: YPLL $=\Sigma$ (ai $\times \mathrm{di}$ ), where ai is the loss of life-years for the age group in question and di is the number of deaths in that age group. The mean YPLL = YPLL divided by number of deaths. ${ }^{15}$

\section{Statistical analysis}

We calculated means \pm standard deviations as summaries of continuous variables. For categorical variables, we computed the percentages of patients of each gender. We compared differences in proportions of men and women using the $\chi^{2}$ test. We expressed numerical variables as means \pm standard deviations and compared differences between proportion of men and women using the Student's $t$-test. We used the computer-based analysis program Statistical Package for the Social Sciences (SPSS) version 13.0 (SPSS Inc, Chicago, IL) for all calculations. We considered differences of $P<0.05$ to be statistically significant.

\section{Results \\ General characteristics}

In this study, we sent out 5900 questionnaires and all were returned. Of these, 5650 questionnaires had been completed 
(by patients aged 40-75 years) and were therefore valid, so the validity was $95.8 \%$. Table 1 shows the relevant general characteristics of these patients. The mean monthly family income of the males was lower than that of the females $(t=-19.51, P<0.001)$.

\section{Differences in behavioral indicators of vulnerability}

There were significant differences between men and women with COPD in the rates of ever, current, passive, and quitting smoking; history of using biomass fuel; average number of years that such fuel had been used; regularly taking exercise; social support; and family history (see Table 2). COPD and its acute exacerbations had forced about $93.4 \%$ of the patients to quit smoking (96.6\% of men versus $94.7 \%$ of women, $P<0.01)$. None of the patients knew how to perform rehabilitative exercises. The male patients had higher rates of ever, current, passive, and quitting smoking and of exercising regularly than did the female patients. Male patients had lower rates of history of using biomass fuel, average duration of using biomass fuel, social support, and family history of COPD than did the female patients.

\section{Differences in indicators of vulnerability involving knowledge, beliefs, and practices}

None of the patients, whether male or female, knew the cause of COPD. In total, 5206 (92.1\%), 2001 (35.4\%), and $3486(61.7 \%)$ patients believed that their disease was caused by colds, smoking, and air pollution (use of biomass fuel), respectively. Of the patients who were smokers, 581 (23.1\%) did not know that smoking could definitely exacerbate their

Table I General characteristics of study patients with chronic obstructive pulmonary disease

\begin{tabular}{llll}
\hline Variable & $\begin{array}{l}\text { Male } \\
(\mathbf{n}=\mathbf{2 8 2 5})\end{array}$ & $\begin{array}{l}\text { Female } \\
(\mathbf{n}=\mathbf{2 8 2 5})\end{array}$ & P value \\
\hline $\begin{array}{l}\text { Age (mean, SD) } \\
\text { Education level (n, \%) }\end{array}$ & $63.7 \pm 8.8$ & $63.6 \pm 9.0$ & $>0.05$ \\
$\quad$ Illiteracy & $1935(68.5)$ & $1935(68.5)$ & $>0.05$ \\
$\quad \begin{array}{l}\text { Primary school } \\
\text { Junior high school }\end{array}$ & $\begin{array}{l}618(21.9) \\
\quad 232(8.2)\end{array}$ & $618(21.9)$ & $>0.05$ \\
$\quad$ High school & $40(1.4)$ & $40(1.4)$ & $>0.05$ \\
$\begin{array}{l}\text { Household population } \\
\text { (mean, SD) }\end{array}$ & $2.9 \pm 8.8$ & $2.9 \pm 8.8$ & $>0.05$ \\
$\begin{array}{l}\text { History years of disease } \\
\text { (mean, SD) }\end{array}$ & $20.9 \pm 14.5$ & $20.9 \pm 14.7$ & $>0.05$ \\
$\begin{array}{l}\text { Family monthly income } \\
\text { (mean, SD) }\end{array}$ & $487.3 \pm 49.6$ & $515.2 \pm 57.7$ & $<0.00 \mathrm{I}$ \\
\hline
\end{tabular}

Abbreviation: SD, standard deviation. disease. In total, 2041 (36.1\%) patients did not know of the relationship between chronic bronchitis and COPD, and did not understand the benefits of preventing chronic bronchitis. Also, 2486 (44.0\%) patients were unaware of the benefits of physical exercise. A total of 3527 (62.4\%) patients believed that they could recover from COPD. Because of their longstanding symptoms of COPD, 624 (11.0\%) patients thought that treatment could not slow the progression of the disease, and $4341(76.8 \%)$ patients were unwilling to adopt helpful measures, such as preventing colds, maintaining a regular vaccination schedule, or having globulin injections. Only $363(6.4 \%)$ patients were unwilling to change their unhealthy behaviors to delay development of the disease. Table 3 shows the differences between male and female patients in these indicators of vulnerability in COPD.

\section{Differences in indicators of vulnerability involving disease management}

None of the patients had participated in any public health education program on COPD because the local health administration had never provided any such programs, eg, about the importance of cessation of smoking or maintaining a nutritious diet for COPD patients. In total, 4937 (87.4\%) patients wanted to be treated but could not comply with recommended treatment for financial reasons. No patients had used inhalers, nebulizer drugs, or oxygen therapy either regularly or temporarily. No patients had attempted pulmonary rehabilitation or surgical treatment. Most patients had received informal and untimely treatment in village or township hospitals. Table 4 shows the different measures used for managing their disease. There were significant differences between male and female patients for all these factors (all $P<0.05$ ).

\section{Differences in economic vulnerability}

In 2008, the yearly net per capita income of a farmer was 6240 yuan (520 yuan per month) in Xuzhou city. The monthly per capita income of patients with COPD was lower than that of the population in general by $32.7 \%$ (27.9\% for male patients and $35.4 \%$ for female patients). Analysis of the annual total medical costs for the 5650 patients showed that these were $11,198,300$ yuan, the per capita economic burden being 1982 yuan. The yearly per capita income of the families of COPD patients was about 5000 yuan, and the yearly direct economic burden for one COPD patient was 1060 yuan. Thus, on average, COPD accounted for one fifth of the patients' families' per capita income. Table 5 shows 
Table 2 Differences in behavioral vulnerability between male and female patients with chronic obstructive pulmonary disease

\begin{tabular}{lllllllllll}
\hline Number & Smoking & $\begin{array}{l}\text { Current } \\
\text { smoking }\end{array}$ & $\begin{array}{l}\text { Passive } \\
\text { smoking }\end{array}$ & $\begin{array}{l}\text { Quit } \\
\text { smoking }\end{array}$ & $\begin{array}{l}\text { History } \\
\text { of using } \\
\text { biomass }\end{array}$ & $\begin{array}{l}\text { Years of using } \\
\text { biomas }^{\mathbf{a}}\end{array}$ & $\begin{array}{l}\text { Physical } \\
\text { exercise }\end{array}$ & $\begin{array}{l}\text { Affect } \\
\text { communication }\end{array}$ \\
\hline hen & 2825 & $69.9 \%$ & $30.1 \%$ & $43.8 \%$ & $56.9 \%$ & $31.5 \%$ & $23.91 \pm 15.86$ & $12.3 \%$ & $61.6 \%$ & $32.9 \%$ \\
Women & 2825 & $19.2 \%$ & $10.9 \%$ & $26.0 \%$ & $42.9 \%$ & $75.3 \%$ & $39.29 \pm 12.90$ & $1.4 \%$ & $74.0 \%$ & $35.6 \%$ \\
Total & 5650 & $44.5 \%$ & $20.5 \%$ & $34.9 \%$ & $51.5 \%$ & $53.4 \%$ & $33.35 \pm 13.82$ & $6.8 \%$ & $67.8 \%$ & $34.2 \%$ \\
$P$ & & $<0.01$ & $<0.01$ & $<0.01$ & $<0.01$ & $<0.01$ & $<0.01$ & $<0.01$ & $<0.01$ & $<0.05$ \\
\hline
\end{tabular}

Note: athe unit of measure is years.

the economic data on patients with COPD. Costs of outpatient services, hospitalization, and long-term self-financed medicines altogether accounted for $94.7 \%$ of COPD-related medical costs. Figure 2 shows the specific categories. Taking into account the yearly net per capita income of the Xuzhou farmers (6240 yuan) in 2008, we estimated the indirect economic loss caused by COPD to be $302,667,744$ yuan in total and 19,344 yuan per capita $(16,044,912$ for male patients and $14,222,832$ for female patients).

\section{Difference in indicators of vulnerability involving quality of life}

The total score for quality of life was significantly lower in female patients than in male patients with COPD. However, there was no significant difference between them in limitation of activities (Table 6). The average potential longevity lost was 1.76 years for men and 1.18 years for women. The average indirect economic burden was 11,158.4 yuan for male patients and 7481.2 yuan for female patients.

\section{Discussion}

The main findings of this study were that there are significant differences between men and women in China with COPD in terms of smoking habits, treatment of their disease, history of using biomass fuel, average potential longevity lost, and cost of COPD.
Risk factors that contribute to development of COPD include smoking, use of biofuels, lack of exercise, social support, work-related dust exposure, and a family history of respiratory disease. ${ }^{16}$ However, in China, there is a difference between men and women in the incidence of COPD. ${ }^{10,17}$ The risk factors for COPD are not the same in women as in men. Therefore, study of the risk factors that cause COPD according to geographical region and gender and of the differences between men and women with regard to indicators of vulnerability to dealing with COPD may provide a scientific basis for designing rational and effective control programs.

This is the first published study on the difference in vulnerability associated with COPD from a gender perspective. After matching 5650 patients (2825 male, 2825 female) with COPD by age ( \pm one year), education level, number of family members ( \pm 1 person), GOLD stage, and duration of disease, we investigated their indicators of vulnerability. We found that patients with COPD in the rural areas of Xuzhou are extremely vulnerable.

Although quitting smoking is the most cost-effective means of preventing further deterioration of lung function, $20.5 \%$ of study patients were current smokers. The rates of ever, current, and passive smoking were all significantly higher in male patients than in female patients. The smoking rate in male patients with COPD was $69.9 \%$, which is

Table 3 Differences in cognitive vulnerability between 5650 male and female patients with chronic obstructive pulmonary disease (\%)

\begin{tabular}{|c|c|c|c|}
\hline & Men & Women & $P$ \\
\hline Thought cold triggered COPD & 90.5 & 86.6 & $<0.01$ \\
\hline Thought smoking triggered COPD & 56.3 & 13.3 & $<0.01$ \\
\hline Thought air pollution triggered COPD & 38.5 & 80.8 & $<0.01$ \\
\hline Did not know that smoking was harmful to COPD & 19.6 & 35.7 & $<0.01$ \\
\hline Did not know the benefit of preventing chronic bronchitis for COPD & 35.6 & 34.2 & $>0.05$ \\
\hline Did not know the benefit of physical exercise for COPD & 41.5 & 43.4 & $>0.05$ \\
\hline Thought treatment could not prevent COPD development & 13.7 & 17.8 & $<0.01$ \\
\hline Unwilling to take active preventive measures, eg, vaccination & 67.1 & 75.3 & $<0.01$ \\
\hline Unwilling to change their bad behavior, eg, quit smoking & 5.5 & 6.8 & $<0.05$ \\
\hline
\end{tabular}

Abbreviation: COPD, chronic obstructive lung disease. 
Table 4 Data concerning disease management methods

\begin{tabular}{|c|c|c|c|c|c|}
\hline Variables & Total n (\%) & Male n (\%) & Female n (\%) & $\chi^{2}$ & $P$ values \\
\hline Took theophylline by mouth at stable stage & 1198 (2I.2\%) & $735(26.0 \%)$ & $463(16.4 \%)$ & 78.4 & $<0.01$ \\
\hline Took theophylline by mouth to treat at exacerbation & $3446(61.0 \%)$ & $1859(65.8 \%)$ & I 587 (56.2\%) & 55.0 & $<0.01$ \\
\hline Used antibiotics to treat at exacerbation & $2980(52.7 \%)$ & $1859(65.8 \%)$ & II2I (39.7\%) & 386.8 & $<0.01$ \\
\hline $\begin{array}{l}\text { Had received inpatient treatment in the township hospitals } \\
\text { due to respiratory symptoms within the past year }\end{array}$ & $1819(32.2 \%)$ & $658(23.3 \%)$ & II6I (4I.I\%) & 205.1 & $<0.01$ \\
\hline
\end{tabular}

significantly higher than that of the general population. ${ }^{18}$ The rate of smoking for men with COPD in our study was similar to that in Spanish men with COPD, whereas the rate for women was lower than that of Spanish women with COPD. ${ }^{19}$ These findings show that the characteristics of smoking behavior, a unique indicator of vulnerability, differ between men and women with COPD.

However, we found that smoking is not the main vulnerable behavior in women with COPD. A history of using biomass fuel and duration of its use was significantly higher in female than in male patients. This is consistent with the fact that women are typically the main family members using biomass in the study locality and shows that smoke generated by using biofuels is of particular relevance to women with COPD. The local kitchens mainly have cornstalk, reed, or earth walls and are not ventilated. The biomass fuel used is derived mainly from straw or charcoal and produces lampblack, which exacerbates any tendency of women to develop COPD. Lampblack is a risk factor that is unique to women with COPD. Family history is also an important risk factor for $\mathrm{COPD},{ }^{20}$ and we found that a family history of COPD was more frequent in female patients than in male patients.

Because lung function tests and health education programs have never been available in the locality of the study patients, none of them had previously heard the term
"COPD" or had been diagnosed as having the condition. Therefore, they had no incentive to acquire knowledge about COPD. There was a significant difference between male and female patients in vulnerability involving knowledge about the causes of COPD. However, vulnerability related to this knowledge correlated with undesirable behavior. For example, because the rate of smoking was higher in male patients, they thought that smoking was an important cause of COPD. In contrast, female patients were more likely to use biomass fuel, so they thought that using biomass was an important cause of COPD.

Because they had not received standard treatment and had longstanding symptoms of COPD, almost $16 \%$ of patients thought that treatment was not capable of slowing the progression of their disease. Female patients were more anxious about this than were male patients. Male patients were more willing to adopt helpful measures, such as preventing colds, maintaining a regular vaccination schedule, or having globulin injections, than were female patients. This may account for the finding that female patients were more likely to be hospitalized than were male patients, and that average medical expenses were lower for men than for women.

Medication is an effective means of preventing and controlling the symptoms of COPD, reducing the frequency and severity of exacerbations, and improving both exercise

Table 5 Differences in disease-related economic indicators

\begin{tabular}{|c|c|c|c|c|}
\hline Variables & Total & Male & Female & $P$ values \\
\hline \multicolumn{5}{|l|}{ Direct economic burden } \\
\hline Mean monthly per capita income of patients with COPD (yuan) & $350 \pm 173$ & $375 \pm 191$ & $336 \pm 162$ & $<0.05^{\#}$ \\
\hline Per capita income of patients was below 350 yuan (n) & $2591(45.9 \%)$ & $1098(38.9 \%)$ & $1493(52.8 \%)$ & $<0.05^{*}$ \\
\hline Mean annual medical expenses (yuan) & & $1686.30 \pm 286.95$ & $2147.26 \pm 363.47$ & $<0.05^{\#}$ \\
\hline Mean annual expenses $<1500$ yuan & & 1237 (43.8\%) & $579(20.5 \%)$ & $<0.05^{*}$ \\
\hline \multicolumn{5}{|l|}{ Indirect economic burden } \\
\hline Mean days being unable to work due to illness (days) & $|20 \pm 3|$ & $96 \pm 35$ & $14 \mid \pm 29$ & $<0.05^{\#}$ \\
\hline Mean days that family members were prevented from working (days) & $55 \pm 12$ & $64 \pm 11$ & $49 \pm 14$ & $<0.05^{\#}$ \\
\hline Number of potential years of life lost (days) & 4850.6 & 2571.3 & 2279.3 & - \\
\hline Mean potential years of life lost (days) & 3.1 & 2.66 & 2.06 & - \\
\hline
\end{tabular}

Notes: "Student's t-test; ${ }^{*} \chi^{2}$ test.

Abbreviation: COPD, chronic obstructive lung disease. 


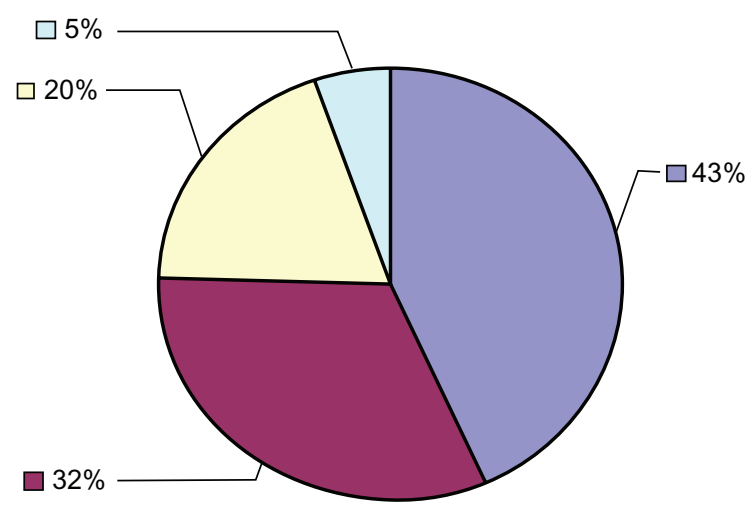

The cost of outpatient services

Hospitalization costs

The long-term selffinanced medicines

Others

Figure 2 Pie graph illustrating the contributions of different categories of medical costs related to chronic obstructive pulmonary disease.

tolerance and quality of life. ${ }^{21,22}$ Providing treatment for COPD patients, especially for those who are stable, can reduce the frequency of exacerbations. ${ }^{23}$ However, we found that patients in rural Xuzhou were highly vulnerable to poor disease management. None of the stable patients had received regular drug treatment, and their drug regimen compliance rate was significantly lower than that reported by Barr et al. ${ }^{24}$ During acute exacerbations of COPD, no patients had used inhalers or sprays. This is much lower than the appropriate rate for use of inhaled drugs, which is $10 \%$ according to Restrepo et al. ${ }^{25}$ Whether male or female, none of the patients knew how to perform rehabilitation exercises and none of them had undergone lung function testing. In the stable and exacerbation stages of COPD, the rate of treatment was higher for male than for female patients. This finding is related to the fact that the household income of female patients is higher than that of males. Because men's earnings are the main income source for families in the study locality, men who are ill are more likely to have treatment to enable them to keep earning wages, whereas women who are ill are more likely to be hospitalized.

We found that the annual direct economic burden of patients with COPD was 1982 yuan, which is lower than in Spain and the US. ${ }^{19,26}$ Although there was no difference between male and female patients in average annual medical expenses, there were more men with medical expenses of less than 1500 yuan per year than there were women. These findings reflect the fact that male patients more often used daily treatment, whereas female patients were more frequently hospitalized. COPD causes loss of potential years of longevity, and these losses were higher than those reported by Fei et al ${ }^{27}$ for both male and female patients. This discrepancy may relate to the fact that our study included rural patients and the studies were performed in different years.

In the present study, the total scores for quality of life were higher for female patients than for male patients. This finding relates mainly to women scoring higher than men in the affect part of the questionnaire we used, which in turn relates to women being more prone to mental illness. ${ }^{28}$ The quality of life aspect of vulnerability reported in this study is higher than that reported by An et al. ${ }^{29}$ This may be because our subjects lived in a rural area.

The present study has a number of limitations. First, its cross-sectional nature predisposes to recall bias and resulting misclassification bias with regard to case status. Second, our estimates of vulnerability may not be applicable to patients with COPD living in other areas, because health care practice patterns may differ regionally. Third, we did not use multiple regression to analyze the reasons for the differences in vulnerability between male and female patients with COPD.

Table 6 Differences between male and female patients with chronic obstructive lung disease $(n=5650)$ in quality of life-related vulnerability

\begin{tabular}{llllll}
\hline & Number & Symptoms & Activity & Psychosocial effects & Total scores of SGRQ \\
\hline Men & 2825 & $71.58 \pm 11.38$ & $73.43 \pm 9.57$ & $73.99 \pm 9.89$ & $71.98 \pm 10.81$ \\
Women & 2825 & $71.39 \pm 11.78$ & $73.45 \pm 10.45$ & $75.30 \pm 10.40$ & $73.66 \pm 10.55$ \\
$P$ & & $>0.05$ & $>0.05$ & $<0.001$ & $<0.001$ \\
\hline
\end{tabular}

Abbreviation: SGRQ, Saint George's Respiratory Questionnaire. 


\section{Acknowledgment}

This work was supported by a grant from the Science and Technology Projects of Xuzhou city in 2007 (XM07C037).

\section{Disclosure}

The authors declare that they have no competing interests in this work.

\section{References}

1. Global initiative for chronic obstructive pulmonary disease. Global strategy for the diagnosis, management, and prevention of chronic obstructive pulmonary disease. Available from: http://www.goldcopd. org/uploads/users/files/GOLD_Report_2011_Jan21.pdf. Accessed November 6, 2012.

2. Mathers CD, Loncar D. Projections of global mortality and burden of disease from 2002 to 2030. PLoS Med. 2006;3:e442.

3. World Health Organisation. The Global Burden of Disease: 2004 update. 2008. Available from: http://www.who.int/healthinfo/global_burden_ disease/2004_report_update/en/index.html. Accessed November 6, 2012.

4. Chan-Yeung M, Aït-Khaled N,White N, Ip MS, Tan WC. The burden and impact of COPD in Asia and Africa. Int J Tuberc Lung Dis. 2004;8:2-14.

5. Zhong N, Wang C, Yao W, et al. Prevalence of chronic obstructive pulmonary disease in China - a large population based spirometry based cross-sectional survey. Am J Respir Crit Care Med. 2007;176: $753-760$.

6. Bureau of Disease Prevention and Control, Ministry of Health of the People's Republic of China, Chinese Center for Disease Prevention and Control. Report on chronic disease in China; 2006:5.

7. Xiaocong F, Xiangdong W, Chunxue B. Burden and importance of proper management about chronic obstructive pulmonary disease in China. Int J Respir. 2011;31:493-497.

8. Fanchen F, Yifeng Y, Gangwen C. Application of vulnerability appraising in constructing theoretical model for early warning of emergent public health event. Acad J Sec Med Univ. 2007;28:116-119.

9. Jinchun C, Aimin W, Feng W. The construction of emergency mechanism and assessment system of emergency public health even. China Inspection and Quarantine. 2007;20:25-26. Chinese.

10. Pixin R, Chen W, Wanzhen Y, et al. The risk factors for chronic obstructive pulmonary disease in females in Chinese rural areas. Chin J Inert Med. 2006;45:974-979.

11. Lou P, ZhuY, Chen PP, et al. Vulnerability, beliefs, treatments and economic burden of chronic obstructive pulmonary disease in rural areas in China: a cross-sectional study. BMC Public Health. 2012; 12:287.

12. Jones PW. Quality of life measurement for patients with disease of the airways. Thorax. 1991;46:676-682.
13. Partridge MR, van der Molen T, Myrseth SE, Busse WW. Attitudes and actions of asthma patients on regular maintenance therapy: the INSPIRE study. BMC Pulm Med. 2006;6:13.

14. Yingyun C, Zuozhe L, Zongjun F. Living quality evaluation of the patients of chronic obstructive pulmonary disease. Chin J Gen Pract. 2004;3:225-227.

15. Centers for Disease Control. Years of potential life lost before ages 65 and 85, United States, 1989-1990. MMWR Morb Mortal Wkly Rep. 1992;41:313-315.

16. Eisner MD, Anthonisen N, Coultas D, et al. An official American Thoracic Society public policy statement: novel risk factors and the global burden of chronic obstructive pulmonary disease. Am J Respir Crit Care Med. 2010;182:693-718.

17. Quanying H, Yanliang M, Rongbao Z, Ruihong Y, Xinli M. Study on the epidemiological difference of four kinds of chronic respiratory diseases in the urban and rural areas of China. Chin J Epidemiol. 2006;27:459-460

18. Peian L, Peipei C, Jiaxi Y, Lei L, Ning Z, Jingde L. A descriptive study on the smoking pattern among general population in Xuzhou, 2008. Chin J Epidemiol. 2010:286-289.

19. Carrasco-Garrido P, Miguel-Díez JD, Rejas-Gutierrez J, et al. Characteristics of chronic obstructive pulmonary disease in Spain from a gender perspective. BMC Pulm Med. 2009;9:2.

20. Nihlen U, Nyberg P, Montnemery P, Löfdahl CG. Influence of family history and smoking habits on the incidence of self-reported physician's diagnosis of COPD. Respir Med. 2004;98:263-270.

21. Zhou Y, Hu G, Wang D, et al. Community based integrated intervention for prevention and management of chronic obstructive pulmonary disease (COPD) in Guangdong, China: cluster randomised controlled trial. BMJ. 2010;341:c6387.

22. Tashkin DP. Long-acting anticholinergic use in chronic obstructive pulmonary disease: efficacy and safety. Curr Opin Pulm Med. 2010; 16:97-105.

23. Miravitlles M. Prevention of exacerbations of COPD with pharmacotherapy. Eur Respir Rev. 2010;19:119-126.

24. Barr RG, Celli BR, Mannino DM, et al. Comorbidities, patient knowledge, and disease management in a national sample of patients with COPD. Am J Med. 2009;122:348-355.

25. Restrepo RD, Alvarez MT, Wittnebel LD, et al. Medication adherence issues in patients treated for COPD. Int J Chron Obstruct Pulmon Dis. 2008;3:371-384.

26. Dalal AA, Christensen L, Fang Liu F, Riedel AA. Direct costs of chronic obstructive pulmonary disease among managed care patients. Int J Chron Obstruct Pulmon Dis. 2010;5:341-349.

27. Fei X, Yaqiong L, Hongbing S, Yaochu X. Years of potential life lost of chronic obstructive pulmonary diseases among residents in Nanjing from 1997 to 2005. Chin J Epidemiol. 2007;28:230204.

28. Laurin C, Lavoie KL, Bacon SL, et al. Sex differences in the prevalence of psychiatric disorders and psychological distress in patients with chronic obstructive pulmonary disease. Chest. 2007;132:148-155.

29. An L, Lin YX, Yang T, et al. Predictive validity of BODE index for anxious and depressive symptoms in patients with chronic obstructive pulmonary disease. Chin Med J (Engl). 2010;123:1845-1851.
International Journal of COPD

\section{Publish your work in this journal}

The International Journal of COPD is an international, peer-reviewed journal of therapeutics and pharmacology focusing on concise rapid reporting of clinical studies and reviews in COPD. Special focus is given to the pathophysiological processes underlying the disease, intervention programs, patient focused education, and self management protocols.

\section{Dovepress}

This journal is indexed on PubMed Central, MedLine and CAS. The manuscript management system is completely online and includes a very quick and fair peer-review system, which is all easy to use. Visit http://www.dovepress.com/testimonials.php to read real quotes from published authors. 